\title{
Serum Antimüllerian hormone does not predict elevated progesterone levels among women who undergo controlled ovarian hyperstimulation for in vitro fertilization
}

\author{
Shahryar K. Kavoussi ${ }^{1 *}$, Shu-Hung Chen ${ }^{1}$, Caitlin L. Hunn ${ }^{1}$, Brady T. West ${ }^{2}$, John David Wininger ${ }^{1}$, \\ Keikhosrow M. Kavoussi ${ }^{1}$ and Parviz K. Kavoussi ${ }^{1}$
}

\begin{abstract}
Serum Antimüllerian hormone (AMH) has been shown to predict various in vitro fertilization (IVF) outcomes. AMH and progesterone $(P)$ are products of granulosa cells of the ovary. Since overall granulosa cell number directly correlates with oocyte number and AMH production, the aim of this study is to evaluate whether or not serum $\mathrm{AMH}$ is associated with elevated $\mathrm{P}$ during controlled ovarian hyperstimulation $(\mathrm{COH})$ for IVF. For this retrospective study, data were abstracted from charts of first IVF cycles of women $(n=201)$ who had undergone $\mathrm{COH}$ between May 2014 and May 2017. Groups were as follows: (A) AMH $<1 \mathrm{ng} / \mathrm{mL}(n=32)$, (B) AMH 1-3.99 ng/mL $(n=109)$, (C), $\mathrm{AMH} \geq 4 \mathrm{ng} / \mathrm{mL}(n=60)$. The primary outcome measure was serum P level at trigger prior to oocyte retrieval. Mean serum $P$ levels among groups $A, B$, and $C$ were $0.92 \mathrm{ng} / \mathrm{mL}, 0.96 \mathrm{ng} / \mathrm{mL}$, and $0.84 \mathrm{ng} / \mathrm{mL}$, respectively. One-way ANOVA showed that there was no difference in mean serum $P$ level among groups $A, B$, and $C(p$-value $=0.28$ ). Multivariable linear regression with $P$ as the dependent variable showed that total gonadotropin dose and peak estradiol level on day of trigger each had a significant positive relationship with $\mathrm{P}$, and clinical pregnancy had a significant negative relationship. Although $\mathrm{AMH}$ is a predictor of certain IVF outcomes, AMH is not a predictor of elevated serum $\mathrm{P}$ level at trigger among women who undergo $\mathrm{COH}$ for IVF.
\end{abstract}

Keywords: AMH, Antimüllerian hormone, IVF, In vitro fertilization, Progesterone

\section{Introduction}

During the process of controlled ovarian hyperstimulation $(\mathrm{COH})$ for in vitro fertilization (IVF) treatment, an elevated serum progesterone $(\mathrm{P})$ level prior to oocyte retrieval may result from the multi-follicular development which is an inherent step prior to oocyte retrieval for IVF. This phenomenon may occur in up to $38 \%$ of $\mathrm{COH}$ cycles, despite the use of gonadotropin releasing hormone $(\mathrm{GnRH})$ analogues [1-3]. Such an early rise in P level is associated with an advancement of the endometrial microarchitecture and the potential for embryonic-endometrial asynchrony

\footnotetext{
* Correspondence: skavoussi@msn.com

${ }^{1}$ Austin Fertility and Reproductive Medicine/Westlake IVF, 300 Beardsley Lane, Bldg B, Suite 200, Austin, TX 78746, USA

Full list of author information is available at the end of the article
}

$[4,5]$. Although controversy exists as to whether or not an elevated serum $P$ level on the day of exogenous follicle triggering has an effect on IVF outcomes [6], many studies, as well as systematic reviews and meta-analyses, have suggested that elevated $\mathrm{P}(\geq 1.5 \mathrm{ng} / \mathrm{mL})$ is associated with lower pregnancy rates $[7,8]$ among women who undergo $\mathrm{COH}$ for IVF, and that a freeze-only of embryos is recommended in that cycle, in order to optimize outcomes by synchronizing the embryo and endometrium in a subsequent, more natural cycle [4].

Antimüllerian Hormone (AMH) is a member of the transforming growth factor (TGF)- $\beta$ superfamily of glycoproteins and a widely-used serum biomarker to assess ovarian reserve in women undergoing $\mathrm{COH}$ for IVF. $\mathrm{AMH}$ is produced by ovarian granulosa cells which

(c) The Author(s). 2019 Open Access This article is distributed under the terms of the Creative Commons Attribution 4.0 International License (http://creativecommons.org/licenses/by/4.0/), which permits unrestricted use, distribution, and reproduction in any medium, provided you give appropriate credit to the original author(s) and the source, provide a link to the Creative Commons license, and indicate if changes were made. The Creative Commons Public Domain Dedication waiver (http://creativecommons.org/publicdomain/zero/1.0/) applies to the data made available in this article, unless otherwise stated. 
surround the primordial to pre-antral ovarian follicles in which oocytes are located [9]. AMH has been shown to be predictive of oocyte yield at retrieval as well as other IVF outcomes [10-13], and this biomarker has been used to optimize $\mathrm{COH}$ protocols that employ exogenous gonadotropins for IVF treatment cycles [14].

Since both the steroid hormone $\mathrm{P}$ and the glycoprotein $\mathrm{AMH}$ are products of granulosa cells [15] and since AMH has been found to be a predictor of several IVF outcomes, the aim of this study is to determine whether AMH predicts the premature $\mathrm{P}$ rise prior to oocyte retrieval. If an association exists, a potential mechanism of action may be elucidated to explain elevated $\mathrm{P}$ and, in cases of intended fresh embryo transfer, patients may be counseled about the likelihood a freeze-only of embryos due to elevated P levels, prior to starting $\mathrm{COH}$ for IVF.

\section{Methods}

A retrospective chart review was performed, with data abstracted from first IVF cycles of women $(n=201)$ who had undergone $\mathrm{COH}$ at Austin Fertility \& Reproductive Medicine/Westlake IVF between May 2014 and May 2017. Inclusion criteria were females between the ages of 18 and 44 years, all causes of infertility, and cases of $\mathrm{COH}$ with exogenous gonadotropins. The exclusion criteria were initial intent of IVF for freeze-only either due to preimplantation genetic testing (PGT) or from an elective standpoint, $\mathrm{COH}$ with oral ovulation induction agents or a combination of oral ovulation induction agents with exogenous gonadotropins, as well as donor oocyte/IVF and donor embryo cases. Due to the de-identified nature of the data collected, Institutional Review Board exemption was obtained from St. David's Healthcare Institutional Review Board.

An AMH level $>1.0 \mathrm{ng} / \mathrm{mL}$, regardless of day of the cycle, was considered as a normal level. Group (A) consisted of women with AMH $<1 \mathrm{ng} / \mathrm{mL}(n=32)$, Group (B) was that of women with AMH of $1-3.99 \mathrm{ng} / \mathrm{mL}(n=109)$, and Group $(\mathrm{C})$ was comprised of women with $\mathrm{AMH} \geq 4$ $\mathrm{ng} / \mathrm{mL}(n=60)$. A high AMH threshold of $4 \mathrm{mg} / \mathrm{mL}$ was used in this study because, in our patient population, a patient is more likely to have a significantly greater ovarian response. In addition, the authors of the following article indicate that an increased risk of severe ovarian hyperstimulation syndrome, consistent with excessive ovarian response, is generally seen in women with AMH level of 4-5 ng/mL [16]. The AMH level was measured (Ansh laboratories, Webster, TX) for each patient within proximity to (at most within 6 months) $\mathrm{COH}$ for IVF. Individualized stimulation protocols with gonadotropin dosage and gonadotropin releasing hormone $(\mathrm{GnRH})$ analogues based on patient $\mathrm{AMH}$ level and age were used, including the $\mathrm{GnRH}$ antagonist protocol which all subjects in Groups B and $\mathrm{C}$ used as well as the majority of subjects in Group A used as two subjects in that groups used the $\mathrm{GnRH}$-agonist microdose flare protocol. During ovarian stimulation with exogenous gonadotropins, serial transvaginal sonograms as well as serum estradiol levels were monitored, with P levels (Roche COBAS ${ }^{\ominus}$ Electrochemiluminescent immunoassay run by Clinical Pathology Laboratories, Austin, TX) being monitored as well, after lead follicle(s) measured $16 \mathrm{~mm}$ or greater in average diameter. After ovarian stimulation and subsequent transvaginal ultrasound-guided oocyte retrieval $35-36 \mathrm{~h}$ after human Chorionic Gonadotropin (hCG) administration, either IVF or intracytoplasmic sperm injection (ICSI) was performed. Embryo transfer was performed on day 3 or day 5 based on embryo quality and in accordance with the American Society for Reproductive Medicine (ASRM) /Society for Assisted Reproductive Technology (SART) guidelines for the number of embryos to be [17]. Surplus good quality blastocysts were cryopreserved on day 5 or day 6.

The primary outcome measure was serum $\mathrm{P}$ level on the day of trigger prior to oocyte retrieval. Secondary outcome measures were number of days of $\mathrm{COH}$, total gonadotropin dosage during $\mathrm{COH}$, number of follicles $>14$ $\mathrm{mm}$ in average diameter on the day of trigger, estradiol level on the day of trigger, number of M2 oocytes at retrieval, and number of 2 pronuclear (2PN) zygotes. Data were expressed as means \pm SD. Statistical analyses were performed with one-way ANOVA and multivariable linear regression. $P$-value $<0.05$ was considered as statistically significant.

\section{Results}

The incidence of elevated progesterone level on the day of trigger for Groups A, B, and C were 15.6\% (5/32), 12.8\% $(14 / 109)$ and $1.7 \%(1 / 60)$, respectively (Chi square: Groups A vs B, $p=0.91$; Group A vs C, $p=0.03$; Groups B vs C, $p=0.03)$. Characteristics and IVF outcomes of women in Group A, B, and C are shown in Table 1. In terms of the primary outcome measure, mean serum $\mathrm{P}$ levels among groups $\mathrm{A}, \mathrm{B}$, and $\mathrm{C}$ were $0.92 \mathrm{ng} / \mathrm{mL}, 0.96 \mathrm{ng} / \mathrm{mL}$, and 0.84 $\mathrm{ng} / \mathrm{mL}$, respectively; there was no statistical difference in mean serum $\mathrm{P}$ level among groups $\mathrm{A}, \mathrm{B}$, and $\mathrm{C}$ ( $p$-value $=0.28$ ). In terms of secondary outcome measures, although there were no differences among groups in for number of days of $\mathrm{COH}$ ( $p$-value $=0.73$ ), there were statistically significant differences among groups for total gonadotropin dosage during $\mathrm{COH}$ ( $p$-value $<0.01$ ), number of follicles $>14$ $\mathrm{mm}$ in average diameter on the day of trigger ( $p$-value $<0.01$ ), estradiol level on the day of trigger ( $\mathrm{p}$-value $<0.01$ ), number of M2 oocytes at retrieval (p-value $<0.01)$, and number of $2 \mathrm{PN}$ zygotes ( $\mathrm{p}$-value $<0.01$ ).

A multivariable linear regression model, with $\mathrm{P}$ as the dependent variable and independent variables shown in Table 2, was fitted, with 166 cases analyzed due to 
Table 1 Variables including demographics and outcomes for study group Group A (women with AMH $<1 \mathrm{ng} / \mathrm{mL}$ ), study Group B (women with $\mathrm{AMH} 1-3.99 \mathrm{ng} / \mathrm{mL}$ ), and study Group C (women with $\mathrm{AMH} \geq 4 \mathrm{ng} / \mathrm{mL}$ )

\begin{tabular}{|c|c|c|c|c|}
\hline Characteristic & $\begin{array}{l}\text { Group A }(n=32) \\
\text { AMH }<1 \mathrm{ng} / \mathrm{mL}\end{array}$ & $\begin{array}{l}\text { Group B }(n=109) \\
\text { AMH } 1-3.99 \mathrm{ng} / \mathrm{mL}\end{array}$ & $\begin{array}{l}\text { Group C }(n=60) \\
\text { AMH } \geq 4 n g / m L\end{array}$ & $P$-value \\
\hline Age (years) & $36.9+/-3.81$ & $34.2+/-4.00$ & $31.3+/-3.85$ & $<0.01$ \\
\hline $\mathrm{AMH}(\mathrm{ng} / \mathrm{mL})$ & $0.576+/-0.28$ & $2.258+/-0.89$ & $6.44+/-2.44$ & $<0.01$ \\
\hline Basal E2 (pg/mL) & $21.47+/-12.07$ & $19.50+/-8.59$ & $23.72+/-11.01$ & 0.03 \\
\hline Basal AFC & $11.32+/-3.64$ & $17.43+/-6.37$ & $25.70+/-7.46$ & $<0.01$ \\
\hline No. of days of $\mathrm{COH}$ & $9.59+/-1.48$ & $9.62+/-1.48$ & $9.433+/-1.56$ & 0.73 \\
\hline Total Gn dose (IU) & $3464.06+/-845.41$ & $2611.24+/-633.16$ & $1838.33+/-636.15$ & $<0.01$ \\
\hline \# follicles $\geq 14 \mathrm{~mm}^{\mathrm{a}}$ & $5.06+/-2.28$ & $9.96+/-4.26$ & $15.233+/-6.29$ & $<0.01$ \\
\hline E2 $(\mathrm{pg} / \mathrm{mL})$ at trigger & $1090.20+/-485.52$ & $1876.66+/-696.30$ & $2371.84+/-890.07$ & $<0.01$ \\
\hline $\mathrm{P} 4(\mathrm{ng} / \mathrm{mL})$ at trigger & $0.92+/-0.60$ & $0.96+/-0.46$ & $0.84+/-0.39$ & 0.28 \\
\hline \# M2 oocytes retrieved ${ }^{b}$ & $4.33+/-3.47$ & $9.06+/-4.51$ & $12.83+/-5.81$ & $<0.01$ \\
\hline \# of 2PN zygotes ${ }^{\mathrm{c}}$ & $3.59+/-2.45$ & $6.43+/-3.96$ & $8.90+/-5.26$ & $<0.01$ \\
\hline CPR (per fresh ET) & $33.3 \%(8 / 24)$ & $52.2 \%(48 / 92)$ & $74.5 \%(38 / 51)$ & $<0.01$ \\
\hline
\end{tabular}

Data are expressed as means +/- SD, and were analyzed via ANOVA*, with AMH as the independent variable for dependent variables/outcomes with the exception of CPR which is expressed as percentages and was analyzed via Fisher's Exact test. $P$-value $<0.05$ was considered statistically significant $A M H=$ Antimüllerian hormone

$A F C=$ antral follicle count

$\mathrm{COH}=$ controlled ovarian hyperstimulation

$C P R=$ clinical pregnancy rate

$E 2$ = estradiol

$E T=$ embryo transfer

$\mathrm{Gn}=$ gonadotropin

$M 2$ = metaphase II

$P 4=$ progesterone

$P N=$ pronuclear

${ }^{a}$ Group A $(n=31)$

${ }^{b}$ Group A $(n=30)$, Group B $(n=108)$; Group C $(n=58)$

'Group A ( $(n=27)$, Group B $(n=107)$; Group C $(n=58)$

Table 2 Multivariate linear regression model using progesterone (P4) as the dependent variable for the listed independent variables

\begin{tabular}{|c|c|c|c|}
\hline \multirow[t]{2}{*}{ Independent variable } & \multicolumn{3}{|l|}{ Progesterone (P4) } \\
\hline & Coefficient (standard errors) & $P$ value & 95\% C.I. \\
\hline Age (years) & $-0.00720(0.00718)$ & 0.316 & $(-0.214,0.007)$ \\
\hline $\mathrm{AMH}(\mathrm{ng} / \mathrm{mL})$ & $-0.01418(0.02127)$ & 0.506 & $(-0.056,0.028)$ \\
\hline Basal E2 (pg/mL) & $0.00106(0.00276)$ & 0.701 & $(-0.044,0.007)$ \\
\hline Basal AFC & $-0.00353(0.00433)$ & 0.416 & $(-0.012,0.005)$ \\
\hline No. of days of $\mathrm{COH}$ & $-0.02756(0.02461)$ & 0.262 & $(-0.076,0.208)$ \\
\hline Total Gn dose (IU) & $0.00017(0.00006)$ & $0.004 *$ & $(0.000,0.003)$ \\
\hline$\#$ follicles $\geq 14 \mathrm{~mm}^{\mathrm{a}}$ & $-0.00301(0.00888)$ & 0.735 & $(-0.205,0.015)$ \\
\hline E2 $(\mathrm{pg} / \mathrm{mL})$ at trigger & $0.00001(0.00005)$ & $0.044 *$ & $(0.000,0.000)$ \\
\hline \# M2 oocytes retrieved ${ }^{b}$ & $0.01693(0.01208)$ & 0.163 & $(-0.007,0.041)$ \\
\hline \# of 2PN zygotes ${ }^{c}$ & $0.00689(0.01218)$ & 0.573 & $(-0.172,0.031)$ \\
\hline CPR (per fresh ET) & $-0.10756(0.05308)$ & $0.044 *$ & $(-0.212,-0.003)$ \\
\hline
\end{tabular}

$A M H=$ Antimüllerian hormone

$A F C=$ antral follicle count

$\mathrm{COH}=$ controlled ovarian hyperstimulation

$C P R=$ clinical pregnancy rate

$E 2$ = estradiol

$E T=$ embryo transfer

$G n=$ gonadotropin

M2 = metaphase II

$P 4=$ progesterone

$P N=$ pronuclear 
missing data on the covariates. Using a $p<0.05$ significance level, total gonadotropin dose and peak estradiol level at trigger had significant positive relationships with $\mathrm{P}$, and clinical pregnancy had a significant negative relationship with $\mathrm{P}$, adjusting for all of the other covariates (Table 2). Based on the fitted model, group B had a significantly higher mean than group A $(p=0.024)$ when adjusting for the other covariates, but overall, group is only marginally significant as a factor $(p=0.07$, based on a Wald test for the two group parameters).

\section{Discussion}

AMH has been shown to be a strong predictor of ovarian response to exogenous gonadotropins during $\mathrm{COH}$ for IVF as well as outcomes such as oocyte yield [18], blastocyst formation [19], blastocyst aneuploidy [20], and surplus embryo cryopreservation at the various stages [21-26]. There are conflicting data regarding the ability of AMH to predict clinical pregnancy rates and live birth rates [27-31].

Freeze-all cycles are more common in recent years and have been instrumental in improving overall IVF and obstetric outcomes; however, there are data that support fresh embryo transfer in subsets of patients [32, 33]. In such cases of patients who initially opt for fresh embryo transfer, the inquiry as to the likelihood of freeze-all due to an elevated progesterone level is sometimes made. A previous publication had found that serum $\mathrm{P}$ level on day of trigger was associated with serum estradiol on the day of trigger, the number of follicles $>14 \mathrm{~mm}$, and the number of oocytes retrieved. The authors found that basal levels of neither follicle stimulating hormone nor estradiol were associated with elevated P; however, AMH was not studied as a potential predictor [34]. Since the glycoprotein AMH is produced by granulosa cells of the ovary and since the steroid hormone $\mathrm{P}$ is also a product of granulosa cells, we hypothesized that AMH may predict elevated P levels during the late follicular phase of $\mathrm{COH}$ with pituitary suppression of $\mathrm{LH}$.

In our study, a one-way ANOVA showed no difference in mean serum $\mathrm{P}$ levels among women grouped into those with $\mathrm{AMH}<1 \mathrm{ng} / \mathrm{mL}$, AMH $1-3.99 \mathrm{ng} / \mathrm{mL}$ and $\mathrm{AMH} \geq 4 \mathrm{ng} / \mathrm{mL}$. Subsequent multivariable linear regression showed that total gonadotropin dose and peak estradiol level at trigger each had a positive relationship with $\mathrm{P}$ level, and clinical pregnancy had a negative relationship with P level. There was weak evidence of group differences based on this model when adjusting for the other covariates, and these differences may become more apparent in future studies with larger sample sizes.

Limitations of our study include the retrospective nature with the inherent biases with such study design. Another study limitation was the sample size, particularly in the low AMH group (Group A). Basal $\mathrm{AMH}$ levels were not checked amongst the patients, which may be considered a minor limitation of this study and may be a potential area to explore in future studies. Although there may have been concerns about luteal deficiency in PCOS, this has predominantly been in the scenario of ovulation induction instead of the $\mathrm{COH}$ protocols used for IVF. A previous study, which involved IVF patients, showed a higher mean progesterone level on the day of trigger among women with PCOS when compared to women without PCOS [35]. Strengths of our study include the use of GnRH antagonist protocols for the vast majority of cases $(94 \%$ of subjects in Group A, 100\% of subjects in Group B, and $100 \%$ subjects in Group C) as well as the use of one laboratory for measurement of $\mathrm{P}$ level. In addition, analysis of this study's data set seemed consistent with the existing literature in terms of showing that AMH was associated with established factors such as ovarian response to exogenous gonadotropins and oocyte yield at retrieval, with there being no difference amongst groups in terms of progesterone level on the day of trigger.

\section{Conclusion}

We conclude that although AMH is a predictor of certain IVF outcomes, AMH is not a predictor of elevated serum $\mathrm{P}$ level at trigger among women who undergo $\mathrm{COH}$ for IVF. Although larger studies are necessary due to the limitations of the retrospective study design and sample size of subjects, these data suggest that the mechanism of action of elevated $\mathrm{P}$ in $\mathrm{COH}$ cycles is unlikely to be due to directly proportionate granulosa cell numbers, and from a clinical standpoint, AMH cannot be used to counsel patients of the likelihood of a freeze-all cycle due to elevated $\mathrm{P}$ if their initial intent is fresh embryo transfer.

\section{Abbreviations \\ AMH: antimüllerian hormone; ASRM: American Society for Reproductive Medicine; $\mathrm{COH}$ : controlled ovarian hyperstimulation; $\mathrm{GnRH}$ : gonadotropin releasing hormone; hCG: human Chorionic Gonadotropin; \\ ICSI: intracytoplasmic sperm injection; IVF: in vitro fertilization; \\ P: progesterone; PGT: preimplantation genetic testing; PN: pronuclear; SART: Society for Assisted Reproductive Technology; TGF- $\beta$ : transforming growth factor- $\beta$}

\section{Acknowledgements}

None.

\section{Funding}

None.

Availability of data and materials

The datasets used and/or analyzed during the current study are available from the corresponding author on reasonable request.

Authors' contributions

All authors (SKK, SHC, CLH, BTW, JDW, KMK, PKK) contributed to the writing process of the manuscript and approved the final version. 


\section{Ethics approval and consent to participate}

Since the dataset was de-identified, this study was granted IRB exemption by St David's Healthcare Institutional Review Board.

\section{Consent for publication}

Not applicable.

\section{Competing interests}

The authors declare that they have no competing interests.

\section{Publisher's Note}

Springer Nature remains neutral with regard to jurisdictional claims in published maps and institutional affiliations.

\section{Author details}

${ }^{1}$ Austin Fertility and Reproductive Medicine/Westlake IVF, 300 Beardsley Lane, Bldg B, Suite 200, Austin, TX 78746, USA. ${ }^{2}$ Institute for Social Research, University of Michigan, Ann Arbor, Ml 48109, USA.

Received: 10 October 2018 Accepted: 28 March 2019

Published online: 08 April 2019

\section{References}

1. Ubaldi F, Bourgain C, Tournaye H, Smitz J, Van Steirteghem A, Devroey P. Endometrial evaluation by aspiration biopsy on the day of oocyte retrieval in the embryo transfer cycles in patients with serum progesterone rise during the follicular phase. Fertil Steril. 1997;67(3):521-6.

2. Bosch E, Valencia I, Escudero $E$, et al. Premature luteinization during gonadotropin-releasing hormone antagonist cycles and its relationship with in vitro fertilization outcome. Fertil Steril. 2003;80(6):1444-9.

3. Lawrenz B, Beligotti F, Engelmann N, Gates D, Fatemi HM. Impact of gonadotropin type on progesterone elevation during ovarian stimulation in GnRH antagonist cycles. Hum Reprod. 2016;31(11):2554-60.

4. Al-Azemi M, Kyrou D, Kolibianakis EM, et al. Elevated progesterone during ovarian stimulation for IVF. Reprod BioMed Online. 2012;24(4):381-8.

5. Li R, Qiao J, Wang L, et al. MicroRNA array and microarray evaluation of endometrial receptivity in patients with high serum progesterone levels on the day of hCG administration. Reprod Biol Endocrinol. 2011;9:29.

6. Griesinger G, Mannaerts B, Andersen CY, Witjes H, Kolibianakis EM, Gordon K. Progesterone elevation does not compromise pregnancy rates in high responders: a pooled analysis of in vitro fertilization patients treated with recombinant follicle-stimulating hormone/gonadotropin-releasing hormone antagonist in six trials. Fertil Steril. 2013;100(6):1622-8.e1-3.

7. Kolibianakis EM, Venetis CA, Bontis J, Tarlatzis BC. Significantly lower pregnancy rates in the presence of progesterone elevation in patients treated with GnRH antagonists and gonadotrophins: a systematic review and meta-analysis. Curr Pharm Biotechnol. 2012;13(3):464-70 Review.

8. Venetis CA, Kolibianakis EM, Bosdou JK, Tarlatzis BC. Progesterone elevation and probability of pregnancy after IVF: a systematic review and metaanalysis of over 60000 cycles. Hum Reprod Update. 2013;19(5):433-57.

9. Dewailly $D$, Andersen CY, Balen A, et al. The physiology and clinical utility of anti-Mullerian hormone in women. Hum Reprod Update. 2014;20(3):370-85.

10. Fiçicioglu C, Kutlu T, Baglam E, Bakacak Z. Early follicular antimüllerian hormone as an indicator of ovarian reserve. Fertil Steril. 2006;85(3):592-6.

11. Nardo $L G$, Gelbaya TA, Wilkinson $H$, et al. Circulating basal anti-Müllerian hormone levels as predictor of ovarian response in women undergoing ovarian stimulation for in vitro fertilization. Fertil Steril. 2009:92(5):1586-93.

12. Lekamge DN, Barry M, Kolo M, Lane M, Gilchrist RB, Tremellen KP. AntiMüllerian hormone as a predictor of IVF outcome. Reprod BioMed Online. 2007;14(5):602-10.

13. Lin WQ, Yao LN, Zhang DX, Zhang W, Yang XJ, Yu R. The predictive value of anti-Mullerian hormone on embryo quality, blastocyst development, and pregnancy rate following in vitro fertilization-embryo transfer (IVF-ET). J Assist Reprod Genet. 2013;30(5):649-55.

14. Fleming R, Broekmans F, Calhaz-Jorge C, et al. Can anti-Müllerian hormone concentrations be used to determine gonadotrophin dose and treatment protocol for ovarian stimulation? Reprod BioMed Online. 2013;26(5):431-9.

15. McNatty KP. Cyclic changes in antral fluid hormone concentrations in humans. Clin Endocrinol Metab. 1978;7(3):577-600.
16. Holte J, Brodin T. High levels of anti-Müllerian hormone: what does this mean for IVF treatment? Expert Review of Endocrinology \& Metabolism. 2013;8(3):209-11.

17. Practice Committee of American Society for Reproductive Medicine; Practice Committee of Society for Assisted Reproductive Technology. Criteria for number of embryos to transfer: a committee opinion.Fertil Steril. 2013;99(1): 44-6.

18. Seifer DB, MacLaughlin DT, Christian BP, Feng B, Shelden RM. Early follicular serum müllerian-inhibiting substance levels are associated with ovarian response during assisted reproductive technology cycles. Fertil Steril. 2002; 77(3):468-71.

19. Arce JC, La Marca A, Mirner Klein B, Nyboe Andersen A, Fleming R. Antimüllerian hormone in gonadotropin releasing-hormone antagonist cycles: prediction of ovarian response and cumulative treatment outcome in good-prognosis patients. Fertil Steril. 2013:99(6):1644-53.

20. Katz-Jaffe MG, Surrey ES, Minjarez DA, Gustofson RL, Stevens JM, Schoolcraft WB. Association of abnormal ovarian reserve parameters with a higher incidence of aneuploid blastocysts. Obstet Gynecol. 2013;121(1):71-7.

21. Lee S, Ozkavukcu S, Heytens E, Moy F, Alappat RM, Oktay K. Anti-Mullerian hormone and antral follicle count as predictors for embryo/oocyte cryopreservation cycle outcomes in breast cancer patients stimulated with letrozole and follicle stimulating hormone. J Assist Reprod Genet. 2011;28(7): 651-6.

22. Majumder K, Gelbaya TA, Laing I, Nardo LG. The use of anti-Müllerian hormone and antral follicle count to predict the potential of oocytes and embryos. Eur J Obstet Gynecol Reprod Biol. 2010;150(2):166-70.

23. Kotanidis L, Asimakopoulos B, Nikolettos N. Association between AMH, oocyte number and availability of embryos for cryopreservation in IVF. In Vivo. 2013;27(6):877-80.

24. Lehmann P, Vélez MP, Saumet J, et al. Anti-Müllerian hormone (AMH): a reliable biomarker of oocyte quality in IVF. J Assist Reprod Genet. 2014;31(4): 493-8.

25. Kavoussi SK, Odenwald KC, Boehnlein LM, et al. Antimüllerian hormone as a predictor of good-quality supernumerary blastocyst cryopreservation among women with levels $<1 \mathrm{ng} / \mathrm{mL}$ versus 1-4 ng/mL. Fertil Steril. 2015; 104(3):633-6.

26. Kotanidis L Nikolettos $K$, Petousis $S$, et al. The use of serum anti-Mullerian hormone (AMH) levels and antral follicle count (AFC) to predict the number of oocytes collected and availability of embryos for cryopreservation in IVF. J Endocrinol Investig. 2016;39(12):1459-64.

27. Reichman DE, Goldschlag D, Rosenwaks Z. Value of antimüllerian hormone as a prognostic indicator of in vitro fertilization outcome. Fertil Steril. 2014; 101(4):1012-8.e1.

28. Merhi Z, Zapantis A, Berger DS, Jindal SK. Determining an anti-Mullerian hormone cutoff level to predict clinical pregnancy following in vitro fertilization in women with severely diminished ovarian reserve. J Assist Reprod Genet. 2013;30(10):1361-5.

29. Bhide P, Gudi A, Shah A, Timms P, Grayson K, Homburg R. Anti-Müllerian hormone as a predictor of pregnancy following IVF. Reprod BioMed Online. 2013:26(3):247-52

30. Goswami M, Nikolaou D. Is AMH Level, Independent of Age, a Predictor of Live Birth in IVF? J Hum Reprod Sci. 2017;10(1):24-30.

31. Alson SSE, Bungum LJ, Giwercman A, Henic E. Anti-müllerian hormone levels are associated with live birth rates in ART, but the predictive ability of anti-müllerian hormone is modest. Eur J Obstet Gynecol Reprod Biol. 2018; 225:199-204.

32. Blockeel C, Drakopoulos P, Santos-Ribeiro S, Polyzos NP, Tournaye H. A fresh look at the freeze-all protocol: a SWOT analysis. Hum Reprod. 2016 Mar;31 (3):491-7.

33. Shi Y, Sun Y, Hao C, et al. Transfer of Fresh versus Frozen Embryos in Ovulatory Women. N Engl J Med. 2018 Jan 11:378(2):126-36.

34. Park JH, Jee BC, Kim SH. Factors influencing serum progesterone level on triggering day in stimulated in vitro fertilization cycles. Clin Exp Reprod Med. 2015:42(2):67-71.

35. Doldi N, Marsiglio E, Destefani A, Gessi A, Merati G, Ferrari A. Elevated serum progesterone on the day of HCG administration in IVF is associated with a higher pregnancy rate in polycystic ovary syndrome. Hum Reprod. 1999 Mar;14(3):601-5. 